\title{
Ratings for Welsh words and their English equivalents
}

\author{
WILLIAM J. FEAR \\ University of Wales College of Cardiff, Cardiff, Wales
}

\begin{abstract}
The rating of English words and their Welsh equivalents provided the opportunity to compare subjective ratings in two languages as well as the opportunity to compare ratings in a deep and a shallow orthography (English and Welsh, respectively). Four variables_age of acquisition (AOA), familiarity, concreteness, and imageability - were rated. AOA and imageability emerged as the two most important extralingual variables ( $r=.8$ and .73 , respectively). Although the patterns of ratings were generally consistent within and between languages, some differences did emerge when these patterns were compared with those from other studies. Using similar instructions to rate familiarity and AOA resulted in a low correlation in English $(r=-.5)$ and a high correlation in Welsh $(r=-.84)$. The mean ratings for familiarity, concreteness, and imageability were higher in Welsh than in English $(5.23 \mathrm{vs.} \mathrm{3.35,5.46}$ vs. 4.41 , and 5.29 vs. 4.38, respectively). Both of these findings are explained in terms of differences in orthographic depth, and it is suggested that Welsh may be a more imageable language than English.
\end{abstract}

The majority of work on word recognition and production has taken place in the English language with monolingual subjects. In the past decade, however, research on word recognition and production has been proceeding in languages other than English, as well as with bilinguals. A developing bilingual literature has begun to focus on cognitive and psycholinguistic issues (see, e.g., Boyce, Browman, \& Goldstein, 1987; Caramazza \& Brones, 1979; Gerard \& Scarborough, 1989). In particular, the work of de Groot and others (see, e.g., de Groot, 1992; de Groot, Dannenburg, \& van Hell, 1994; de Groot \& Nas, 1991) has begun to develop a strong theoretical foundation for bilingual word recognition based on shared conceptual representations of words. Bilingualism potentially presents some of the strongest challenges-outside of multilingualism-to existing theories of lexical processing, which are based on monolingual research. At the same time, it has the potential to present powerful evidence in support of these theories.

A related line of developing research compares word recognition and production in deep and shallow orthographies; such a comparison allows an important variable in word recognition-orthography-to be manipulated (see, e.g., Frost, 1994; Frost, Katz, \& Bentin, 1987; Katz \& Feldman, 1983). A deep orthography is one in which the spelling-to-sound rules are inconsistent. That is, a

This study was based in part on an MSc (Econ) dissertation submitted in partial fulfillment of the requirements for the MSc degree at the University of Wales College of Cardiff. The research was supported by Grants K00429413158 and R00429534381 from the Economic and Social Research Council. I would like to thank Diane Ellis and C. Barry for their help and support during the research. Thanks are also extended to the two reviewers of this paper for their comments and suggestions. Correspondence should be addressed to W. J. Fear, School of Psychology, University of Wales College of Cardiff, PO Box 901, Cardiff CF 1 3YG, Wales (e-mail: sapwjf@cardiff.ac.uk). word cannot always be correctly read aloud according to a set of rules for translating graphemes into phonemes. English is such a language, with large numbers of irregular words, homophones, homonyms, and so on. The majority of models of reading, and the dominant dual-route model especially, are based on the English language. The dual-route model conveniently fits the behavior of a deep orthography like English, since it proposes that the primary route for word recognition is by direct visual access, hence allowing irregular words to be read without regularization errors. The phonological route, in which words are read using grapheme-to-phoneme correspondences (GPCs), is used only for reading novel words, including nonwords, since they do not have an existing lexical representation.

A shallow orthography is one in which the spelling-tosound rules are consistent. That is, a word can always be correctly read aloud according to a set of rules for GPCs. Serbo-Croation, Spanish, and Welsh are examples of such languages. Shallow orthographies have few, if any, irregular words, homophones, or homonyms, although some of these word types will almost always occur due to specific features of a language. Research that exploits languages with shallow orthographies is presenting a growing body of evidence that challenges the assumptions underlying the existing dual-route models, and even the models themselves (see, e.g., Bosman \& de Groot, 1995; Carello, Lukatela, Peter, \& Turvey, 1995; Katz \& Feldman, 1981; Lukatela, Gligorijević, Kostić, \& Turvey, 1980).

Three major features make the case of Welsh-English bilingualism particularly useful for this line of research. First, Welsh-English bilinguals speak two languages that have opposite orthographic depths: Welsh has a shallow orthography and English has a deep orthography. However, both languages share a similar structure and have almost all the same sounds (D. Brown, 1976; Price, 1984), 
although the GPCs are not always the same between languages. Second, as a language, Welsh may behave differently from English as a result of its linguistic environment. Historically, Welsh is an older and more literary language than English. It is also a less used language, having in the United Kingdom around 500,000 speakers; 300,000 people who can speak, read, and write it; and 200,000 people who use it on a daily basis. Despite its low rate of use, Welsh is considered a high-status language in parts of Wales, and there is a Welsh language television channel, a Welsh language radio station, and Welsh language schools. A further example is that road signs are presented in both English and Welsh throughout Wales. A final point on the Welsh language is that the vast majority of Welsh speakers are also bilingual in English (Aitchison \& Carter, 1994). There are few, if any, monoglot Welsh speakers.

A further point that has received much interest but has not been highly researched (and is not addressed in this work) is that Welsh has a fixed and rule-governed mutation system. Mutations occur in Welsh when the initial consonants of Welsh words change under some circumstances according to fixed and definite rules, without changing the meaning of the word. For example, $p$ changes to $/ \mathrm{b} /, / \mathrm{mh} /, / \mathrm{ph} /$ in some circumstances. Thus /pensil/ (pencil) becomes /bensil/,/mhensil/,/phensil/.

One of the important rated variables recognized in the English monolingual literature is familiarity, or subjective frequency, which is sometimes used in place of objective frequency counts, concreteness, imageability, and age of acquisition (AOA) (see Carroll \& White, 1973; Gilhooly \& Hay, 1977; Gilhooly \& Logie, 1980; Quinlan, 1992). The terms familiarity and subjective frequency are used interchangeably in this paper, and unless stated as objective frequency, any reference to frequency should be taken to indicate "subjective frequency" or "familiarity."

AOA, the age at which people think they acquired a word, has been reemerging as an important variable in cognitive and psycholinguistic research. It has been demonstrated as both valid and reliable (see Chappel, Morrison, \& Ellis, 1996: Gilhooly \& Gilhooly, 1979, 1980; but see Forster, 1992, for an alternative argument supporting frequency) and is beginning to receive attention, particularly with regard to lexical and semantic processing. This variable is important because in some word processing tasks, it emerges as having an effect that is separate from that of objective word frequency measures (see, e.g., Coltheart, Laxon, \& Keating, 1988; Morrison, Ellis, \& Quinlan, 1992). Thus it potentially provides a challenge to models of reading that are based on word frequency as the dominant variable for word recognition and production. At present, the strongest hypothesis is that the effect of AOA is located in the phonological output lexicon (G. D. A. Brown \& Watson, 1987). Brown and Watson suggested that words learned early in life may have stronger and more complete representations in the phonological output lexicon and are accessed more easily. Words learned later have less complete representations, and so more as- sembling must take place for these words. Thus, AOA measures may indeed make a valuable contribution to language research.

As yet, no one seems to have developed any bilingual measures for AOA. Subjective frequency seems to have been the primary variable considered in most experimental investigations into shallow orthographies, at least those studies that have contributed to theory on the influence of orthography on word recognition. In contrast, there seems to be little evidence that the variables AOA, imageability, and concreteness have been collected for equivalent words in two languages, although de Groot (1992) and de Groot et al. (1994) did collect, among other data, subjective ratings for imageability and familiarity for 458 equivalent Dutch and English words. They also had access to objective frequency ratings for both the Dutch and the English words from the CELEX database (see Burnage, 1990). They found extralingual intercorrelations of . 94 for imageability, .63 for familiarity, and .78 for objective $\log$ frequency.

A number of questions emerge. First, can the same subjective ratings of variables be collected in both deep and shallow orthographies? If they can be collected, will they show the same pattern of intercorrelations in both languages? Second, if ratings of equivalent words are collected from these two orthographies, what pattern of intra- and extralingual intercorrelations will emerge? Finally, as would be expected if AOA is the same variable as familiarity, will AOA be highly correlated with familiarity if the same instructions are used to collect each of these two variables? The present study begins to address these questions, with the additional feature that the language with a shallow orthography (Welsh) is spoken by bilinguals.

It is assumed that the patterns of intralingual intercorrelations within each language will mirror each other and, similarly, that patterns of extralingual intercorrelations will be consistent across languages. Predictions cannot be made about levels of correlation, since these may be dependent on specific language features and on the selection of words. AOA should emerge as the same variable as familiarity when the same instructions are given for rating both AOA and frequency.

\section{METHOD}

\section{Subjects}

For convenience, both Welsh-English and English-Welsh bilinguals are referred to as "Welsh-English bilinguals." For descriptive purposes only, they may be considered as compound bilinguals (Ervin \& Osgood, 1954). That is, linguistically they behave as though they have a single representation for equivalent words in their two languages. All Welsh-speaking subjects were considered to be relatively highly fluent in both Welsh and English.

For the Welsh AOA ratings, Welsh-English bilingual subjects were drawn from three sources: final year pupils in two Welshmedium ${ }^{1}$ high schools (age range $=16$ years, 6 months to 18 years, 6 months) and adult Welsh-English bilinguals in the community ( $n=68$; mean age $=21$ years; 34 females, 33 males, 1 unknown; 35 first-language Welsh, 32 first-language English, 1 unknown). The primary language in Welsh-medium schools is Welsh. Pupils in 
Welsh-medium schools have been educated through a system similar to immersion education and are considered to be fully bilingual (see Baker, 1985, 1988, for further discussion). Many of them are from English-speaking homes, and they enter the education system at 3 years of age, when they begin to attend nursery classes. From then on they are taught mainly through the Welsh language, although a portion of their education is in English. All Welsh-English bilingual subjects were asked to complete an AOA rating form in both Welsh and English, though not all did so. None of these subjects received payment for their participation.

The Welsh-English bilingual subjects who provided ratings for Welsh frequency $(n=19$; mean age $=29$ years; 8 female, 9 male, 2 unknown; language details unknown), concreteness $(n=13$; mean age $=23$ years; 11 female, 2 male; 6 first-language Welsh, 7 firstlanguage English), and imageability ( $n=13$; mean age $=23$ years; 11 female, 2 male; 7 first-language Welsh, 6 first-language English) were drawn from the population of Welsh-speaking undergraduates in the Welsh Department at the University of Wales College of Cardiff(UWCC), as well as from members of the Welsh-speaking community in Cardiff and the surrounding area. The undergraduate Welsh speakers are taught solely through the medium of Welsh; all their exams and essays are in the medium of Welsh. All subjects were paid a small amount per completed rating form for their participation.

For the English AOA ratings, the subjects were drawn from third (i.e., final) year undergraduates in the education department at UWCC, and from the same pool of subjects who rated the words for Welsh AOA $(n=58$; mean age $=26$ years; 40 female, 18 male; 31 first-language English, 26 first-language Welsh, 1 unknown). These subjects participated voluntarily and did not receive any remuneration for their participation. English AOA ratings were the only ratings taken from both monolinguals and bilinguals. The ratings for the two groups correlated at .92 and were combined to give the English AOA ratings used here. Monolingual subjects for English frequency ratings were selected by asking all available pupils of 16 years, 6 months to 18 years, 6 months of age in a single comprehensive English-medium school to participate $(n=42$; mean age $=$ 17 years; 20 female, 20 male, 2 unknown; all first-language English). These subjects participated voluntarily and did not receive payment. Monolingual English subjects for the concreteness and imageability ratings were drawn from first-year undergraduates in the psychology department at UWCC and received $2 \mathrm{~h}$ of course credit for their participation ( $n=14$; mean age $=20$ years; 11 female, 3 male; all first-language English for both groups).

\section{Instruments}

A list of 705 English and Welsh equivalent words ${ }^{2}$ to be rated for AOA, familiarity/frequency, imageability, and concreteness were taken from Fear (1995). All of these words can be used as nouns in both languages. When the ratings were collected, the order of the words on the forms was determined by sorting Welsh words in English alphabetical order and English words in Welsh alphabetical order. This sorting rendered a partially scrambled order to the words.

There was some variety in the way in which ratings were collected. For all AOA ratings, individual subjects rated approximately one half of the total list in English, Welsh, or both. Similarly, for English frequency measures only, individual subjects rated approximately one half of the total list. For the remaining measures of Welsh frequency, as well as concreteness and imageability in both languages, all subjects rated the full list of 705 words. In the case of concreteness and imageability, the same subjects all rated the full list of 705 words for both of these variables.

Instructions on the English rating forms were given in English and those on the Welsh rating forms were given in Welsh. All instructions were initially written in English and then translated into Welsh by a professional translator. Thus English and Welsh rating forms had equivalent instructions. Rating scales ranged from 1 to 7 for all ratings, with 1 as the lowest rating and 7 as the highest rating. This system allowed for consistency of rating scales across the variables.

Collection of AOA ratings entailed a problem: How were subjects to be asked to rate words for AOA when they may not have started to learn one of the languages until, say, the age of 3 or 4 years (as in the case of Welsh)? The solution was to instruct the subjects to rate words without providing specific anchor points (in contrast to Gilhooly and Logie's, 1980, ratings). Rather, subjects were instructed as follows:

On the following pages you will find a list of words. Each word is to be given a rating from 1 through to 7 indicating when you think you first learned the word. If you learned the word early on in your life, then you give it a score of 1 , and if you learned the word later in your life, you give it a score of 7 . There is no exact age for the ratings and no one correct answer for any of the words. Any words you do not know should be rated as 7 .

As an example take the word $\operatorname{dog}$. If you learned this word when you were 2 years old, you give it a score of, say, 1 . If you did not learn the word until you were 6 , then you would give it a score of, say, 3. As a further example, let us take the word infallibility. If you learned this word when you were 10 , you would give it a score of, say, 5 , and if you did not learn the word until you were 13 or older, you would give it a score of, say, 7

There is no one correct answer for any of the words and everybody will rate them slightly differently. Remember, the rating scale goes from I to 7 , with 1 indicating "early" and 7 indicating "late."

The same instructions and examples were supplied for frequency ratings, with 1 indicating extremely infrequent and 7 indicating extremely frequent. All references to AOA were replaced by references to frequency (i.e., the frequency with which the rater thinks the word occurs).

For imagery ratings, the instructions from Paivio, Yuille, and Madigan (1968) were used. These instructions requested the rater to rate words from 1 to 7 , depending on the word's strength of image. A rating of 1 was to be given to words with low imageability and a rating of 7 to words with high imageability. Anchor points were not used; rather, an example was provided. For concreteness, the instructions from Spreen and Schulz (1966) were used. Raters were requested to rate words as high in concreteness if they referred to objects, materials, or persons, and as low in concreteness if they referred to abstract concepts. Again, anchor points were not used; an example was given.

All rating procedures were consistent across variables in that all ratings were explained, and examples given, without recourse to anchor points, and all used the same number of rating points on the rating scale.

\section{Procedure}

Ratings forms were distributed and collected in the form of stapled A4-size booklets (page size approximately $29.5 \times 20.8 \mathrm{~cm}$ ). Booklets for the AOA ratings and the English frequency ratings were all approximately 10 pages long, and booklets for all other variables were approximately 19 pages. No instructions were given other than those on the rating form itself, as well as the verbal instruction to complete the form as quickly as possible. Time taken to complete the scales varied, but was typically $7-10$ days.

In order to ensure some variation between subjects' ratings forms, every other form listed the second half of the list of words first. When the same subjects were rating words for both concreteness and imageability, two alternately ordered forms were provided.

\section{Analysis}

Mean ratings were determined by collapsing ratings for each word across subjects. All mean ratings, with their standard deviations. are given in the Appendix. The list is also available from the author on disc in PC or Macintosh format, either as an Excel file or as a plain text file. 
Table 1

English Intercorrelations and Summary Data

\begin{tabular}{lcccc}
\hline \multicolumn{1}{c}{ Variables } & AOA & Familiarity & Concreteness & Imageability \\
\hline AOA & - & & & \\
Familiarity & -.5 & - & & \\
Concreteness & -.57 & .04 & - & - \\
Imageability & -.67 & .18 & .86 & \\
& & & & \\
$M$ & 3.34 & 3.35 & 4.41 & 4.38 \\
SD & 1.12 & 1.06 & 1.36 & 1.37 \\
Intergroup & & & .84 & .85 \\
$\quad$ reliability & .93 & .85 & .84 & .88 \\
\hline $\begin{array}{l}\text { Correlation with } \\
\text { Quinlan (1992) }\end{array}$ & .95 & .81 & .92 & \\
\hline
\end{tabular}

Note-AOA, age of acquisition.

Intercorrelational analyses were performed using SPSS (Version 6.0) for Windows. The English ratings were also correlated with existing ratings for AOA, familiarity, imageability, and concreteness taken from the Quinlan (1992) database. All correlations given are significant at the $p<.05$ level at least.

Intergroup reliabilities were determined by dividing each group of raters for each variable into two subgroups. Correlations were calculated between subgroup scores on each variable. This is the method used by de Groot (1992), de Groot et al. (1994), and Gilhooly and Logie (1980).

\section{RESULTS AND DISCUSSION}

The extralingual intercorrelations emerged as follows: AOA $(.8)>$ imageability $(.73)>$ concreteness $(.71)>$ familiarity $(.58)>\log$ frequency ${ }^{3}$ (objective) (.25). This is the same pattern for the rated variables of imageability and familiarity as that in de Groot et al. (1994), which yielded the following: imageability $(.94)>\log$ frequency (objective) (.78) > familiarity (frequency) (.63). There was a difference in terms of the position of the extralingual log-frequency (objective) correlation, and this may be attributable both to language features and to the differing strengths of the log-frequency correlations. However, more importantly for this study, the patterns for the subjectively rated variables (imageability and familiarity) were the same across studies. Of the variables rated, AOA and imageability emerged as potentially the two most important extralingual variables for equivalent words.

With one exception, the pattern of intralingual intercorrelations between the rated measures in English (Table 1) was consistent with that between the measures given in Gilhooly and Logie (1980), which in turn matched those of Gilhooly and Hay (1977), Paivio et al. (1968), and Toglia and Battig (1978). The relationship between familiarity (frequency) and AOA ( $r=-.5$ ) was considerably weaker than that found in Gilhooly and Logie $(r=$ -.72 ). This weak correlation also altered the pattern of intercorrelations. A lower or higher correlation could be interpreted in terms of selection of stimuli, but an alteration in the pattern requires a different interpretation. One possibility is that this alteration was due to the instructions on the ratings forms. The absence of anchor points in the instructions for rating AOA (and frequency) may have affected AOA (and frequency) ratings. Similarly, giving the same instructions for frequency ratings and AOA ratings may have affected the ratings.

Familiarity, or subjectively rated frequency, emerged as distinct from AOA, at least for English, since even when the same instructions were used for rating both variables, the correlations were not high enough to suggest that familiarity and AOA are the same. Furthermore, the results showed that AOA is a relatively robust variable in terms of its rateability even though anchor points were not used. Correlations between the ratings collected in the present study and those of Quinlan (1992), together with the intergroup correlations for each variable, confirm that the present ratings are reliable.

In regard to the intralingual intercorrelations for the Welsh words (Table 2), no comparative measures are available, as far as I know. However, the pattern of intralingual intercorrelations for the Welsh words matched that for English words in Gilhooly and Logie (1980) without any disturbances. Although AOA seems to be a robust and reliably rateable measure in Welsh, its high level of intercorrelation with familiarity indicates that in Welsh, unlike English, these two variables may indeed be the same. This in turn contradicts the explanation that the low correlation found for the English ratings may be an effect of the instructions. An alternative explanation is pursued below, but some effect of instruction type cannot be completely ruled out. In other words, using instructions to rate for AOA without anchor points and using the same instructions for frequency may have yielded differential effects on subjective ratings in Welsh and English and may have had differential effects in English compared with previous ratings that have made use of anchor points for AOA ratings. However, the degree of effect that such a difference in instructions may have had cannot be determined on the basis of the present results.

The intragroup correlations for each variable are the only measures available for indicating reliability. Since these correlations are high for all variables, they are taken as an indication of an acceptable level of reliability.

An interpretation of the differences between the strength of correlation between AOA and familiarity in Welsh and English is considered below together with the following point. The mean ratings in Welsh for familiarity, concreteness, and imageability were higher than the same mean ratings in English (5.23 vs. 3.35, 5.46 vs.

Table 2

Welsh Intercorrelations and Summary Data

\begin{tabular}{lcccc}
\hline \multicolumn{1}{c}{ Variables } & AOA & Familiarity & Concreteness & Imageability \\
\hline AOA & - & & & \\
Familiarity & -.84 & - & & \\
Concreteness & -.72 & .67 & - & - \\
Imageability & -.74 & .67 & .95 & 5.29 \\
$M$ & & & & 1.27 \\
$S D$ & 3.44 & 5.23 & 5.46 & .8 \\
Intergroup & 1.21 & 1.48 & 1.23 & .85 \\
$\quad$ reliability & .92 & .88 & & \\
\hline
\end{tabular}

Note-AOA, age of acquisition. 
$4.41,5.29$ vs. 4.38 , respectively). It may be that because the English raters were monolingual and the Welsh raters were bilingual, the latter made some sort of extralingual comparison. However, an alternative explanation is plausible: These differences may be due to language features.

Specifically, Welsh has a shallow orthography: There are no irregular words and few homophones. It is not necessary to learn more than one set of rules for GPCs, novel words can be read relatively easily, and it may be that all words look, and sound, relatively familiar. There is a far smaller core of discrete words in Welsh than in English. A large number of words can be derived from a relatively small sample, since the root word is often highly preserved and recognizable within derived words (see Jones, 1994, who has created a dictionary of approximately 10,000 Welsh words derived from 400 words). Awberry and Meara (1992) found a large range of difficulty in a small sample (approximately 4,000 words) of Welsh "head words" and pointed out that the same level of difficulty cannot be found in an equivalent sample of English words. It is possible that although all words may look more familiar in Welsh, resulting in a higher mean familiarity rating, the spread of difficulty across a small core of words means that difficult words are quite simply not used very much, from a subjective viewpoint, and as a result are not learned until later in life (and vice versa for easy words). This would account for the high correlation between AOA and familiarity. Furthermore, Welsh has a strong and ancient literary tradition. Although the language does not lend itself well to scientific usage, it is extremely powerful as a conveyor of artistic expression. As a result, it may be that Welsh words produce far stronger pictorial conceptual representations than do English words-that is, Welsh is a more imageable language than is English. Hence, the mean correlations in concreteness and imageability are higher.

English has a deep orthography and is replete with irregular words, homophones, and so on. Because the spelling-to-sound rules are inconsistent, English words are not always easily recognizable and may not look, or sound, familiar. Most irregular words also tend to be monosyllabic high-frequency words. Words in English are often not derived from existing words but are borrowed or created anew, resulting in a large and discrete set of words. It is, therefore, reasonable to assume that some words that are, for whatever reason, less familiar, may be learned early in English - words that require a knowledge of exceptions to the rule and that are thus possibly used less in some subjective, perhaps verbal, context, are learned early in life. Together with this, words that follow GPC rules may not be learned until later in life, although they may then be used relatively frequently from a subjective viewpoint. This would account for the lower correlation between AOA and familiarity. In other words, in English some words that are used infrequently and that are difficult (i.e., unfamiliar) are learned early, and some words that are used frequently and that are easy (i.e., familiar) are learned later.
Taking all these points into account, it is not unreasonable to assume that it is the behavior of the language, or its features, as evidenced by subjective ratings, that accounts for both the higher mean ratings in Welsh and the higher correlation between Welsh AOA and familiarity.

Finally, these ratings were not collected under laboratory conditions; as such, they can in part be taken as a function of the amount of variance due to interference from extraneous variables in fieldwork of this type. That is, any differences between the present ratings and equivalent measures in other studies may be due in part to interference. This is an important consideration, since it is not always possible to collect ratings, or even to conduct experiments, within the laboratory. Nonetheless, the variables examined in the present study do demonstrate a high degree of reliability and robustness.

\section{REFERENCES}

Aitchison, J., \& CARTER, H. (1994). A geography of the Welsh language. Cardiff: University of Wales Press.

AWBERRY, G. M., \& MEARA, P. (1992). Graded Welsh vocabulary tests. University College Swansea, Centre for Applied Language Studies, Swansea, U.K.

BAKER, C. (1985). Aspects of bilingualism in Wales. Clevedon, U.K.: Multilingual Matters.

BAKER, C. (1988). Key issues in bilingualism and bilingual education. Clevedon, U.K.: Multilingual Matters.

Bosman, A. M. T., \& DE Groot, A. M. B. (1995). Evidence for assembled phonology in beginning and fluent readers as assessed with the first-letter-naming task. Journal of Experimental Child Psychology, 59, 234-259.

Boyce, S., Browman, C. P., \& Goldstein, L. (1987). Lexical organization and Welsh consonant mutations. Journal of Memory \& Language, 26, 419-452.

Brown, D. (1976). Gramadeg Cymraeg Cyfoes. Y Bontfaen Morgannwg. Brown, G. D. A., \& WATSON, F. L. (1987). First in, first out: Word learning age and spoken word frequency as predictors of word familiarity and word naming latency. Memory \& Cognition, 15, 208-216.

Burnage, C. (1990). CELEX: A guide for users. Njimegen, the Netherlands: SSN.

Caramazza, A., \& Brones, I. (1979). Lexical access in bilinguals. Bulletin of the Psychonomic Society, 13, 212-214.

Carello, C., Lukatela, G., Peter, M., \& Turvey, M. T. (1995). Effects of association, frequency, and stimulus quality on naming words in the presence or absence of pseudowords. Memory \& Cognition, 23, 289-300

Carroll, J. B., \& White, M. (1973). Age of acquisition norms for 220 picturable nouns. Journal of Verbal Learning \& Verbal Behavior, 12 , 563-576.

Chappel, T., Morrison, C., \& Ellis, A. (1996). An objective measure of word learning age [Abstract]. Proceedings of the British Psychological Society, 4(1).

Coltheart, V., Laxon, V., \& Keating, C. (1988). Effects of word imageability and age of acquisition on children's reading. British Journal of Psychology, 79, 1-12.

DE GROOT, A. M. B. (1992). Determinants of word translation. Journal of Experimental Psychology: Learning, Memory, \& Cognition, 18, 10011018.

de Groot, A. M. B., Dannenburg, L., \& van Hell, J. G. (1994). Forward and backward word translation by bilinguals. Journal of Memory \& Language, 33, 600-629.

DE Groot, A. M. B., \& NAS, G. L. J. (1991). Lexical representations of cognates and noncognates in compound bilinguals. Journal of Memory \& Language, 30, 90-123.

ERvin, S., \& OsGoon, C. (1954). Second language learning and bilingualism. Journal of Abnormal \& Social Psychology, 49 (Suppl.), 134-146. 
FEAR, W. J. (1995). Age of acquisition and frequency effects in WelshEnglish bilinguals. Unpublished MSc dissertation, University of Wales, Cardiff.

FORSTER, K. (1992). Memory-addressing mechanisms and lexical access. In R. Frost \& L. Katz (Eds.), Orthography, phonology, morphology \& meaning (pp. 413-434). Amsterdam: Elsevier.

Frost, R. (1994). Prelexical and postlexical strategies in reading: Evidence from a deep and a shallow orthography. Journal of Experimental Psychology: Learning, Memory, \& Cognition, 20, 116-129.

Frost, R., KATZ, L., \& BeNTIN, S. (1987). Strategies for visual word recognition and orthographical depth: A multilingual comparison. Journal of Experimental Psychology: Human Perception \& Performance, 13, 104-115.

Gerard, L. D., \& Scarborough, D. L. (1989). Language-specific lexical access of homographs by bilinguals. Journal of Experimental Psychology: Learning, Memory, \& Cognition, 15, 305-315.

Gil HOOLY, K. J., \& GILHOOLY, M. L. M. (1979). Age-of-acquisition effects in lexical and episodic memory tasks. Memory \& Cognition, 7, 214-223.

Gilhooly, K. J., \& Gilhooly, M. L. M. (1980). The validity of age-ofacquisition ratings. British Journal of Psychology, 71, 105-1 10.

GILHOOLY, K. J., \& HAY, D. (1977). Imagery, concreteness, age-ofacquisition, familiarity, and meaningfulness values for 205 five-letter words having single-solution anagrams. Behavior Research Methods \& Instrumentation, 9, 12-17.

GilHoOLY, K. J., \& LoGIE, R. H. (1980). Age-of-acquisition, imagery, concreteness, familiarity, and ambiguity measures for 1,944 words. Behavior Research Methods \& Instrumentation, 12, 395-427.

JoNES, G. (1994). Welsh roots and branches. Bwlch, Wales: Tre Graig.

KaTZ, L., \& FeldMAN, L. B. (1981). Linguistic coding in word recognition. In A. M. Lesgold \& C. A. Perfetti (Eds.), Interactive processes in reading (pp. 85-105). Hillsdale, NJ: Erlbaum.

KATZ, L., \& FELDMAN, L. B. (1983). Relation between pronunciation and recognition of printed words in deep and shallow orthographies. Journal of Experimental Psychology: Learning, Memory, \& Cognition, 9. 157-166.

KuČERA, H., \& FranCES, W. (1967). Computational analysis of presentday American English. Providence, RI: Brown University Press.
Lukatela, G., Gligorijević, B., Kostić, A., \& Turvey, M. T. (1980) Representation of inflected nouns in the internal lexicon. Memory \& Cognition, 8, 415-423.

Morrison, C. M., Ellis, A. W., \& Quinlan, P. T. (1992). Age of acquisition, not word frequency, affects object naming, not object recognition. Memory \& Cognition, 20, 705-714.

OGWEN, E., \& Jenkins, H. E. (1978). Dysgu Darllen (laith a diddordebau plant). London and Basingstoke: Macmillan.

Paivio, A., Yuille, J. D., \& Madigan, S. A. (1968). Concreteness, imagery and meaningfulness values for 925 nouns. Journal of Experimental Psychology Monographs, 76(1, Pt. 2), 1-25.

PrICE, G. (1984). Welsh as a literary, standard, and official language. In M. J. Ball \& G. E. Jones (Eds.), Welsh phonology (pp. 262-269). Cardiff: University of Wales Press.

QUINLAN, P. T. (1992). The Oxford psycholinguistic database. Oxford: Oxford University Press.

SPREeN, O., \& SchUlz, R. W. (1966). Parameters of abstraction, meaningfulness and pronounceability for 329 nouns. Journal of Verbal Learning \& Verbal Behavior, 5, 459-468.

Toglia, M. P., \& BAtTIG, W. F. (1978). Handbook of semantic word norms. Hillsdale, NJ: Erlbaum.

\section{NOTES}

1. Medium refers to the "medium of instruction"-the language used to teach in the school (not to the pupils' ages).

2. All words have the same dictionary translations both ways. For example, $c i$ translates to $d o g$, and $d o g$ translates to $c i$.

3. Kučera and Frances's (1967) counts were used for the English, and Ogwen and Jenkins's (1978) counts were used for the Welsh. These are two different methods of collecting and developing frequency counts. Whereas Kučera and Frances give the number of occurrences per million of words in a selected sample of different texts, Ogwen and Jenkins give the number of occurrences of each word per approximately 120,000 in a sample of spoken and written language produced by children of $4-8$ years. 


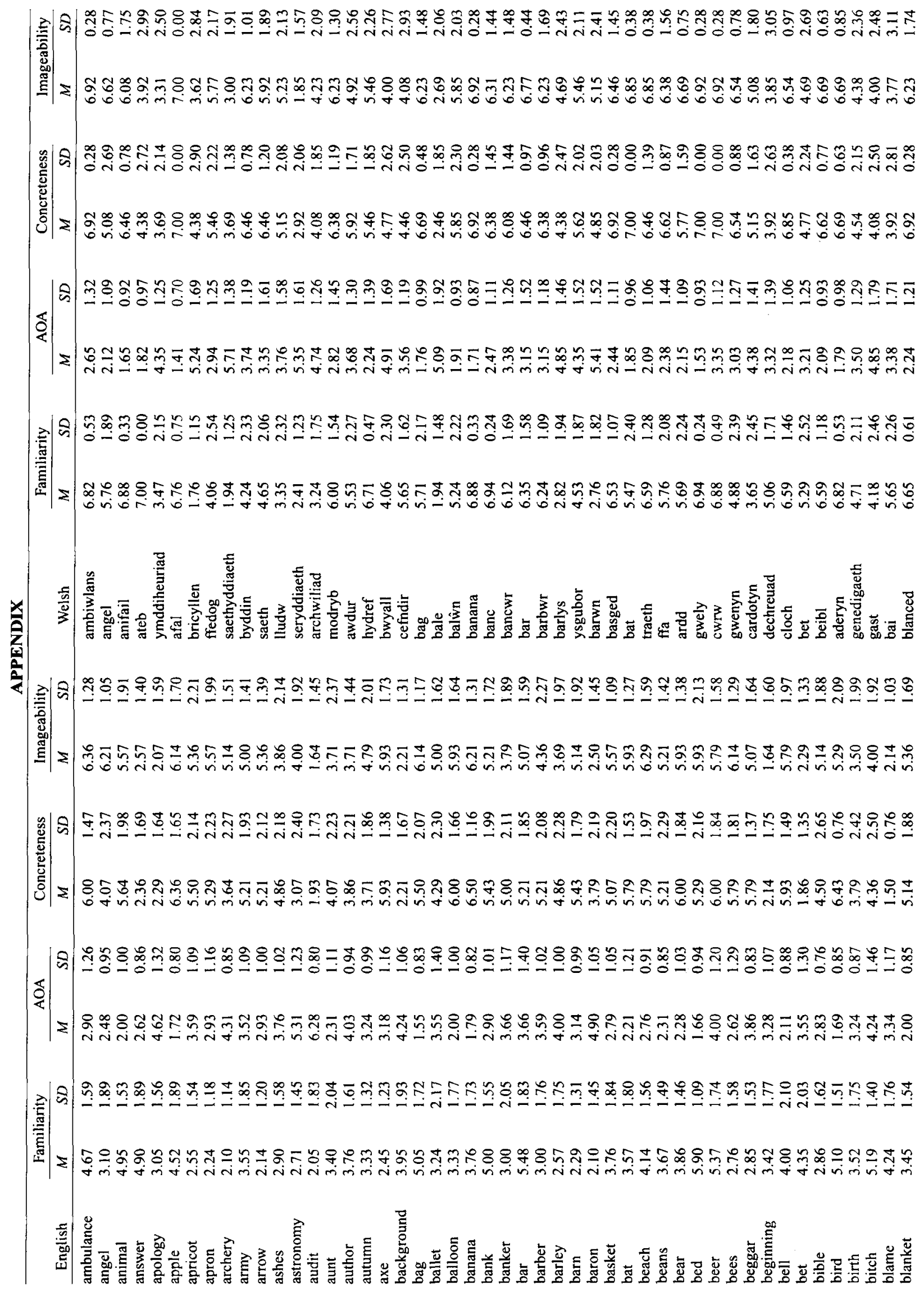




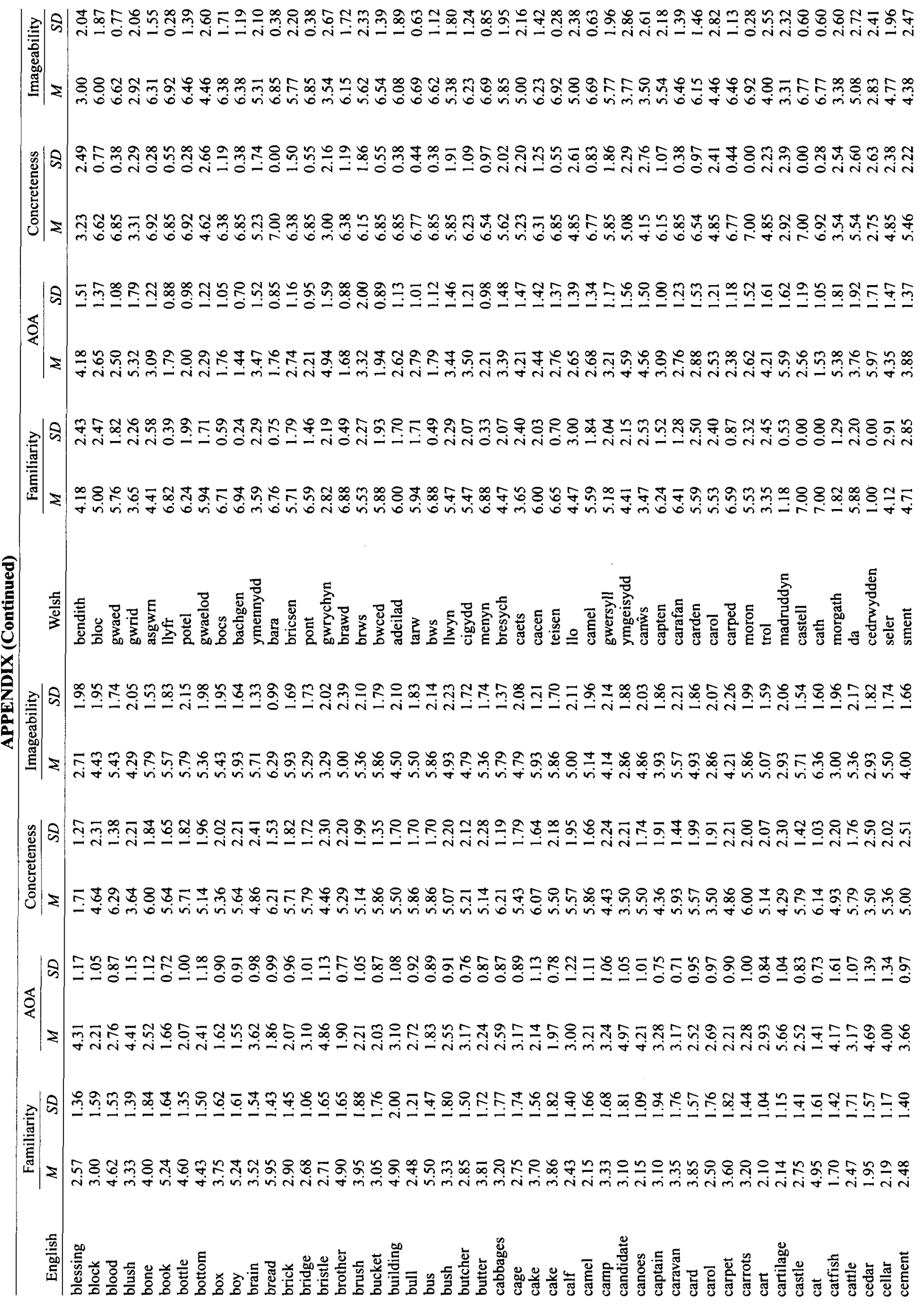




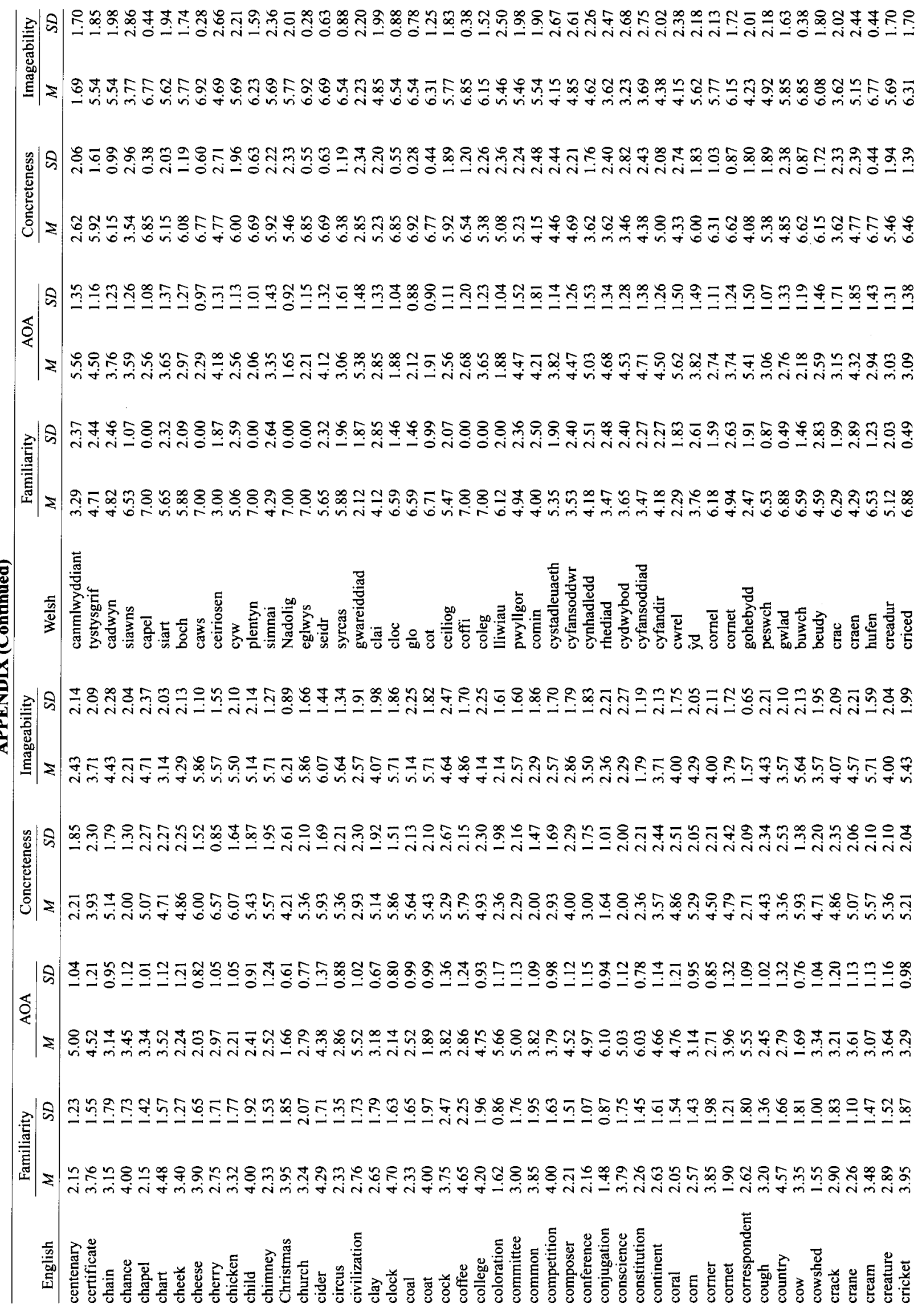




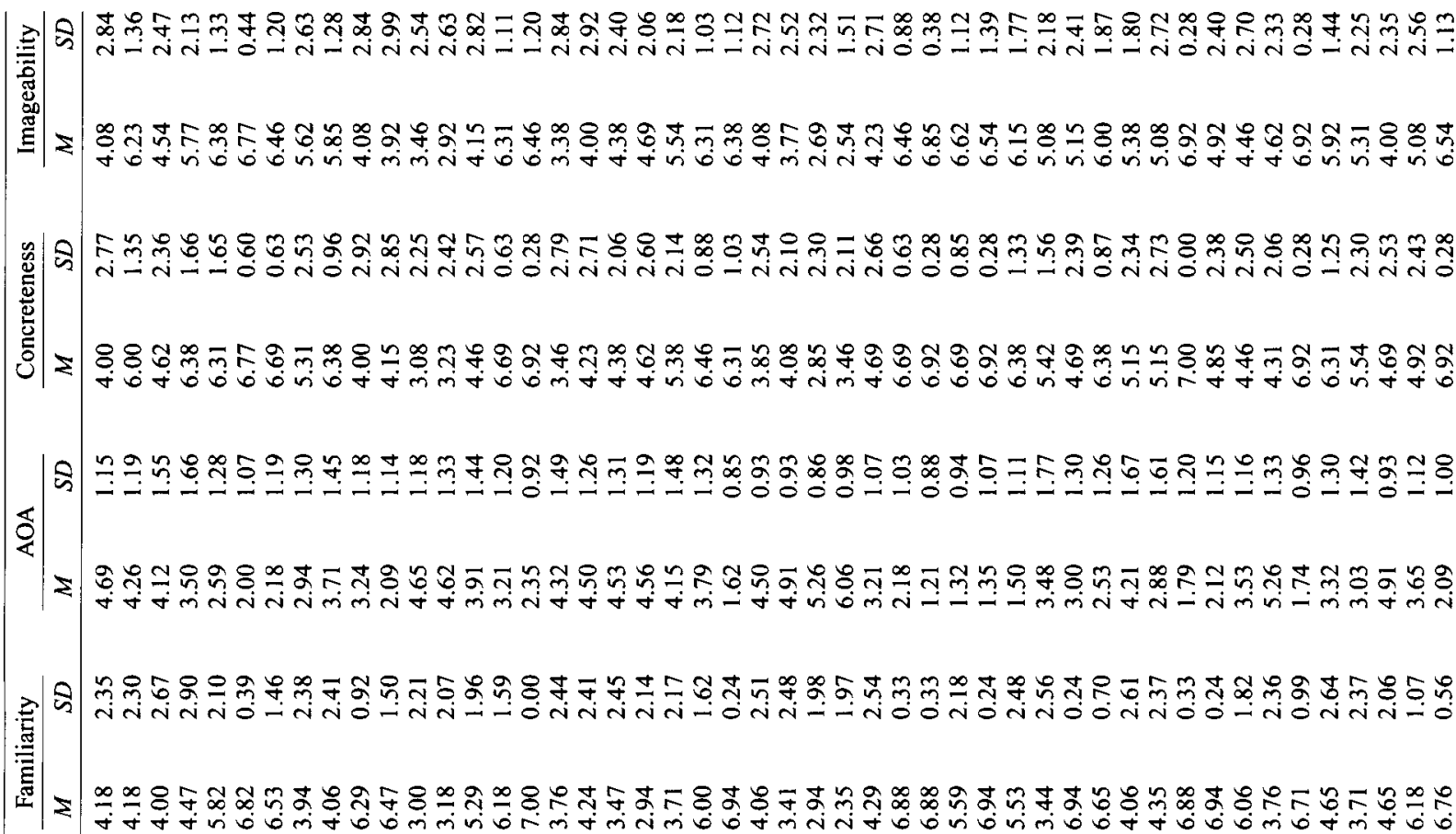

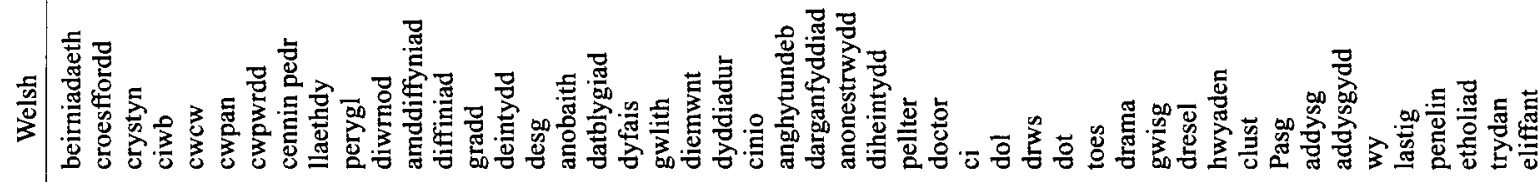

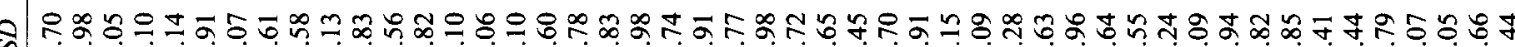

₹

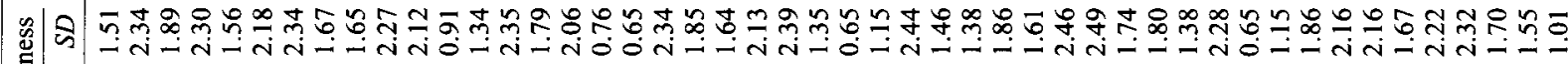

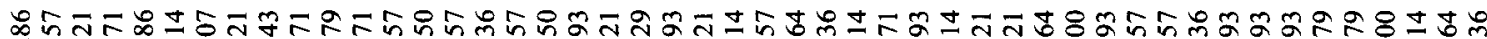

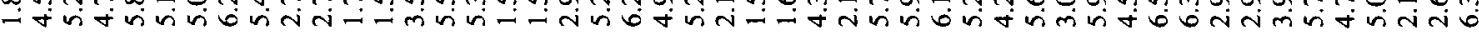

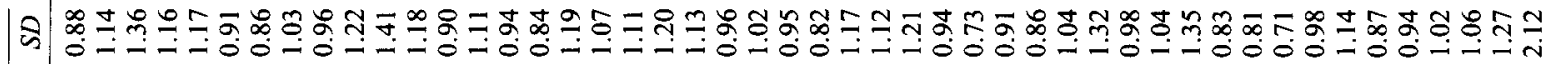
爻

క

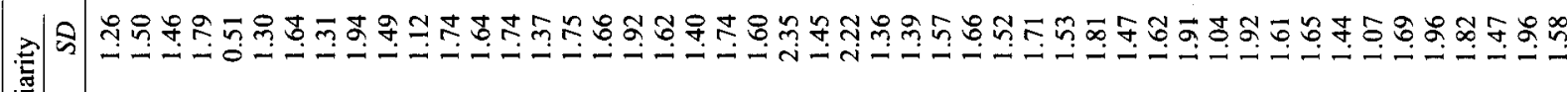

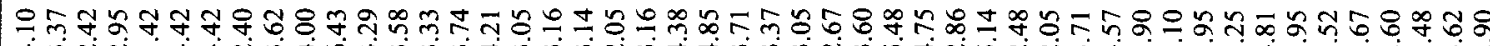

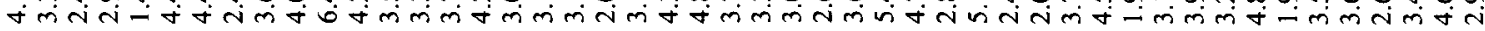

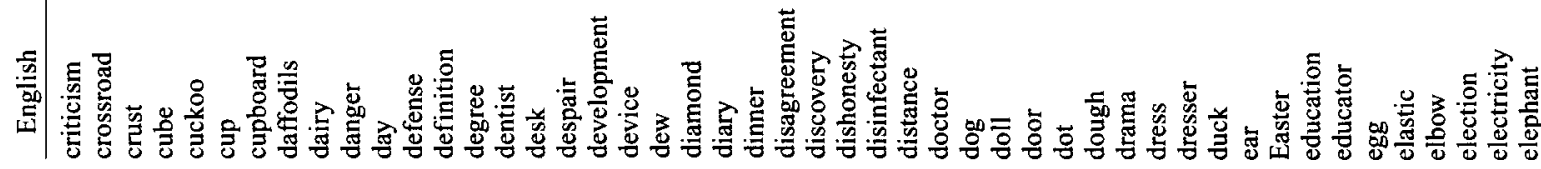




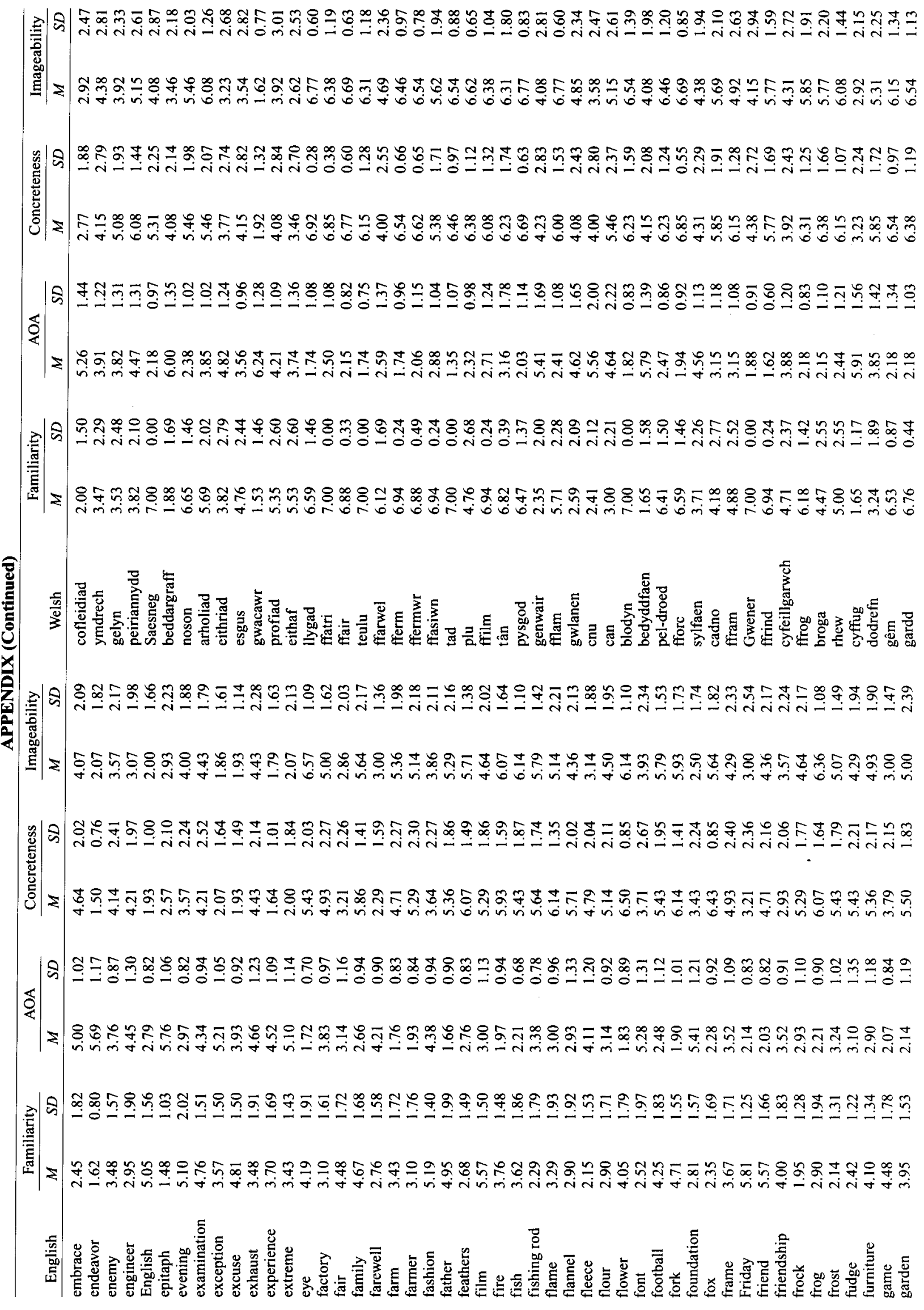




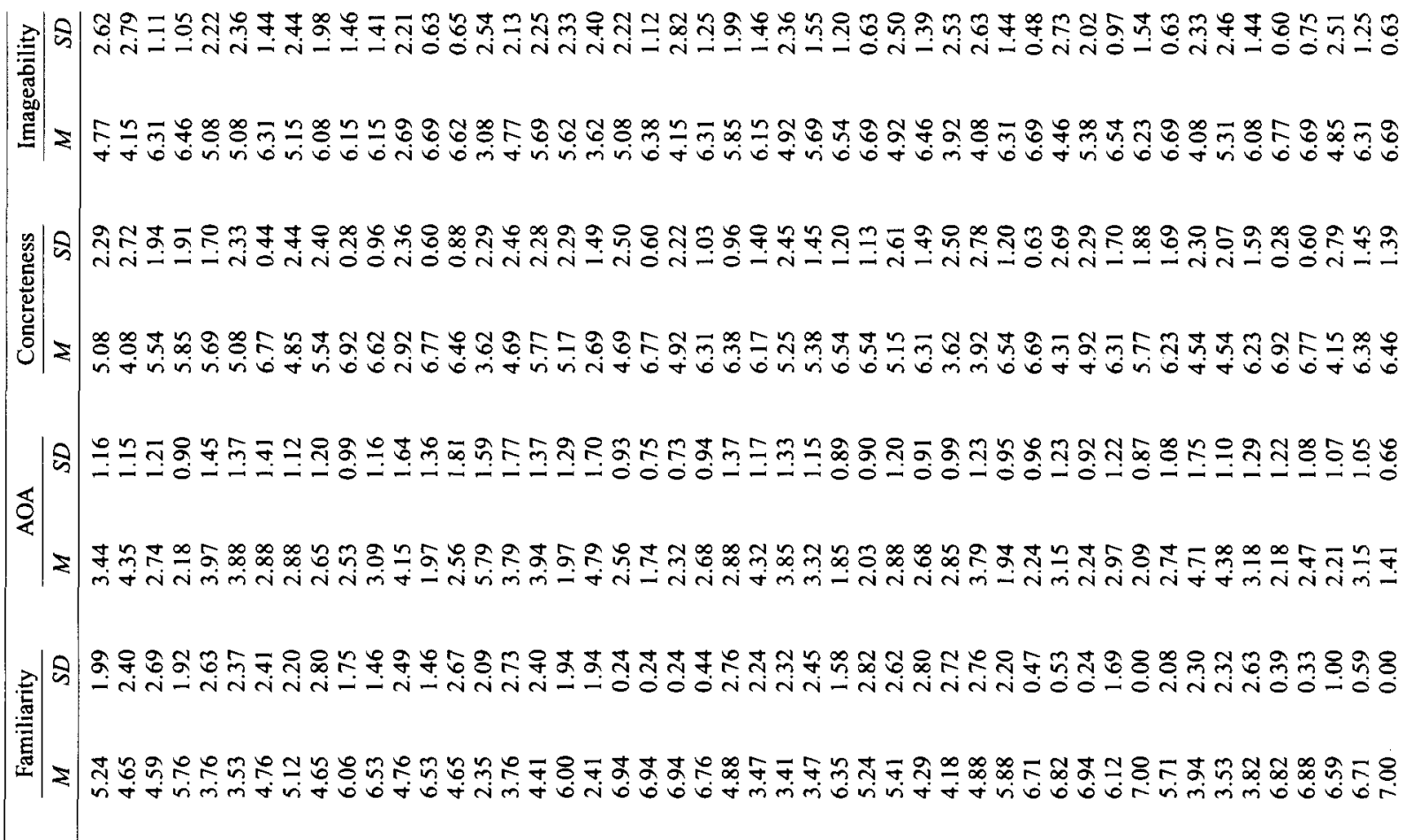
要

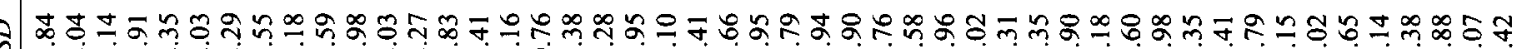

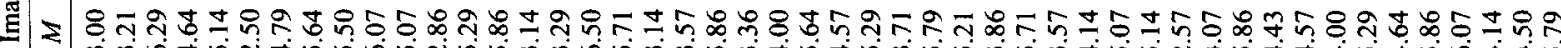

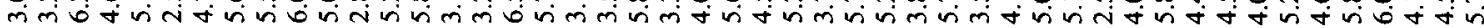

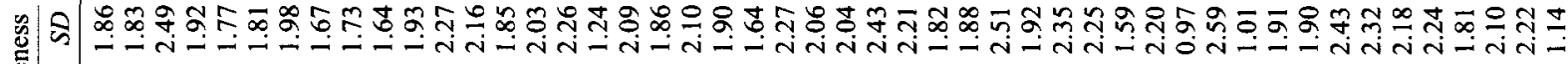

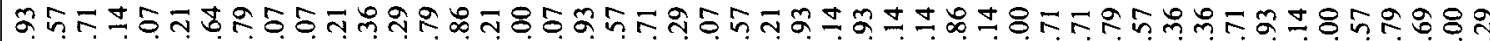

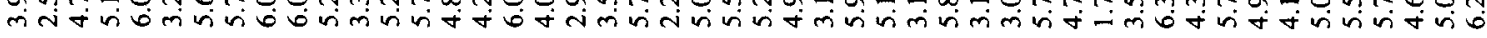

ฐ̊

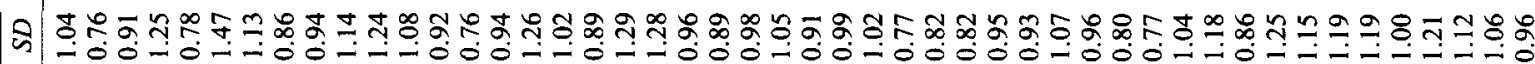

₹

른

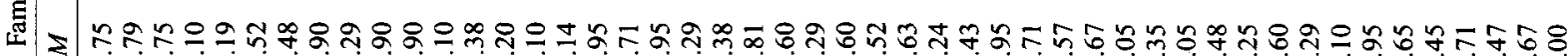

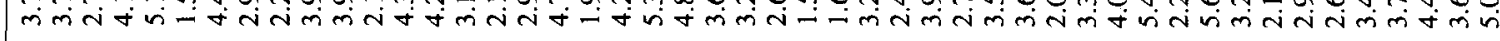

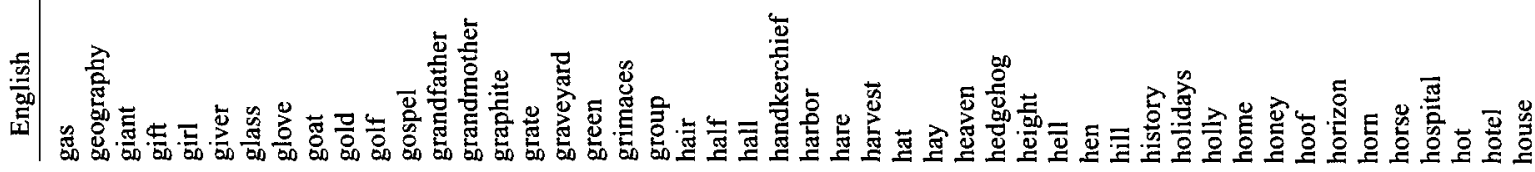




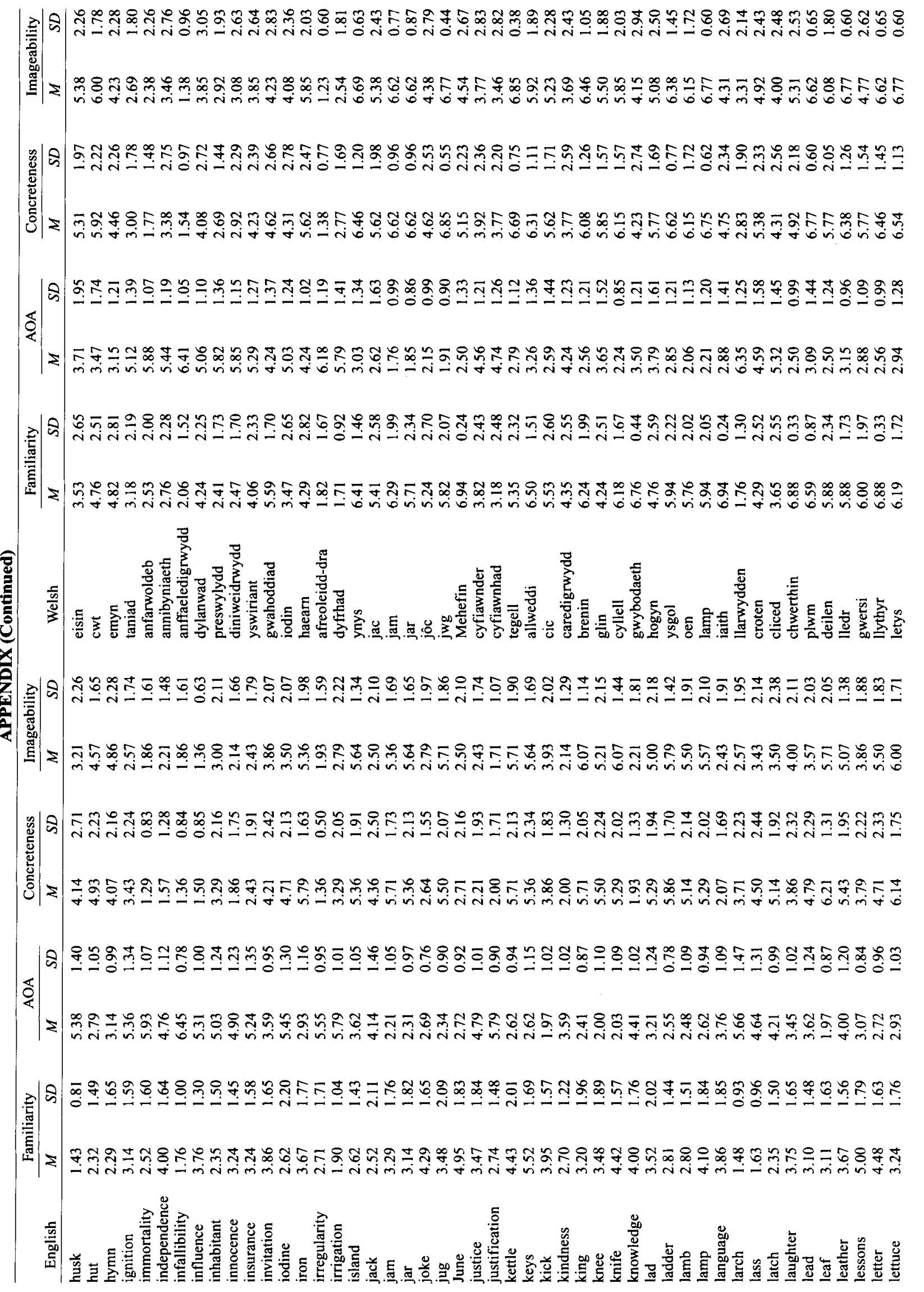




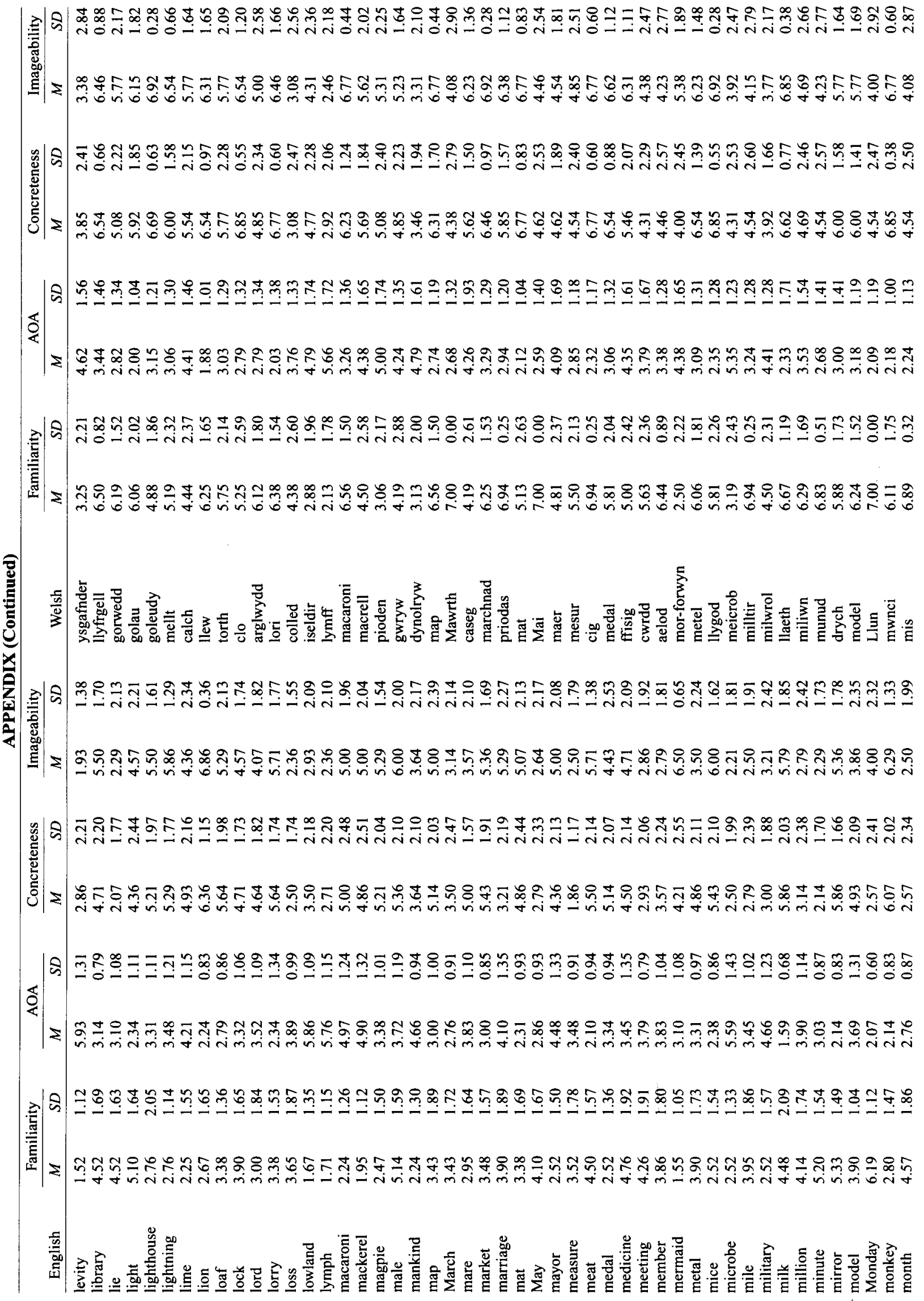




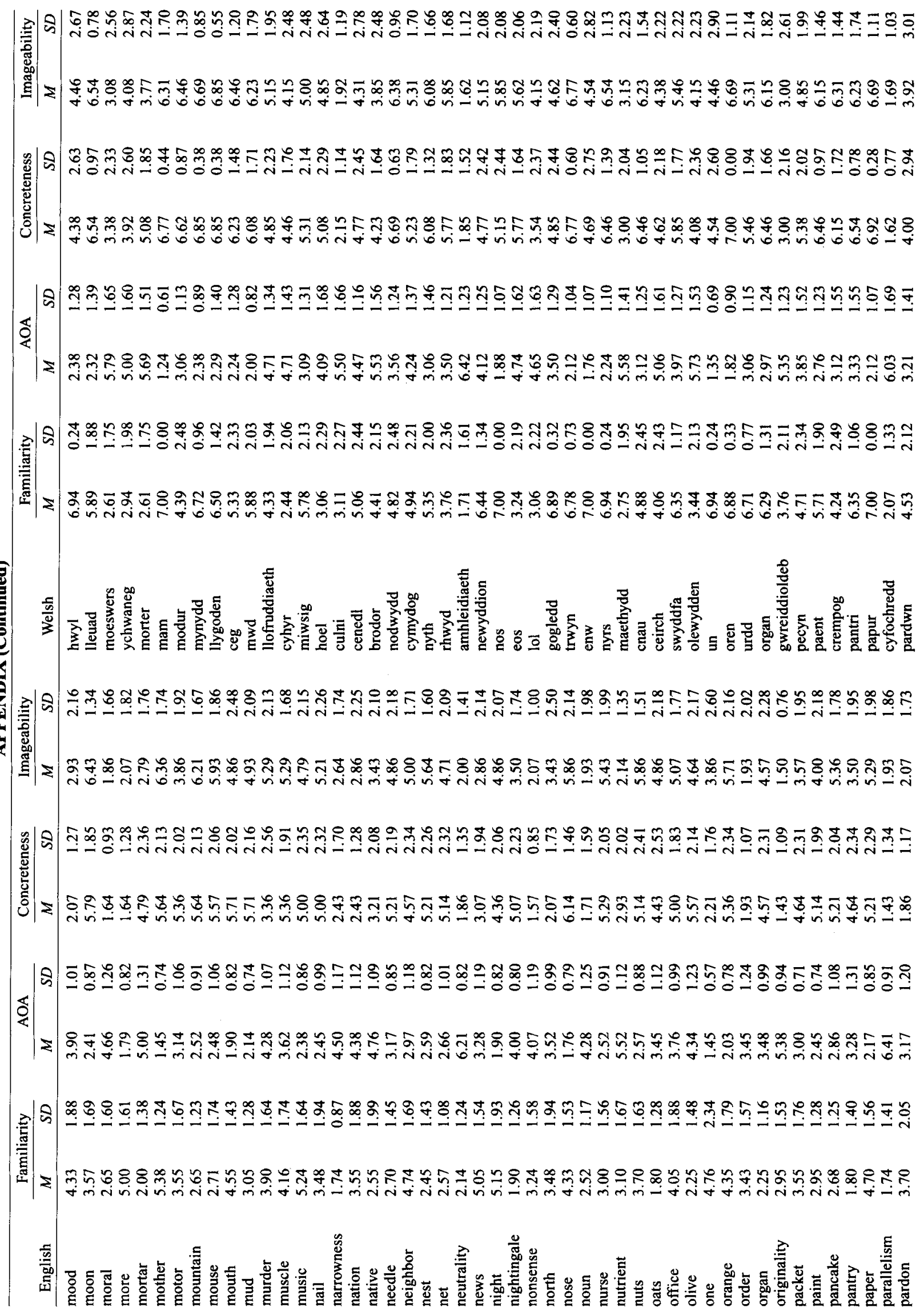




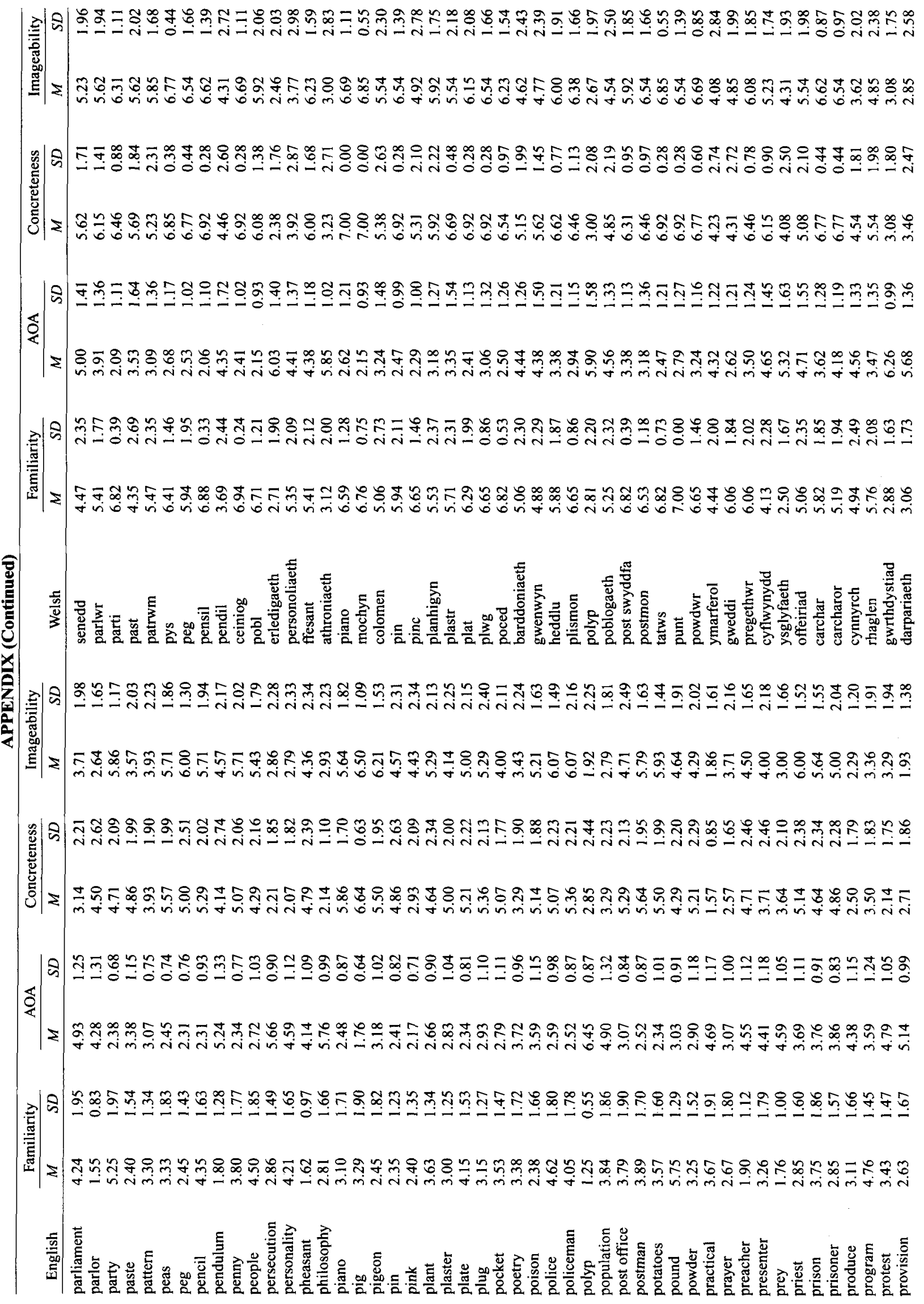




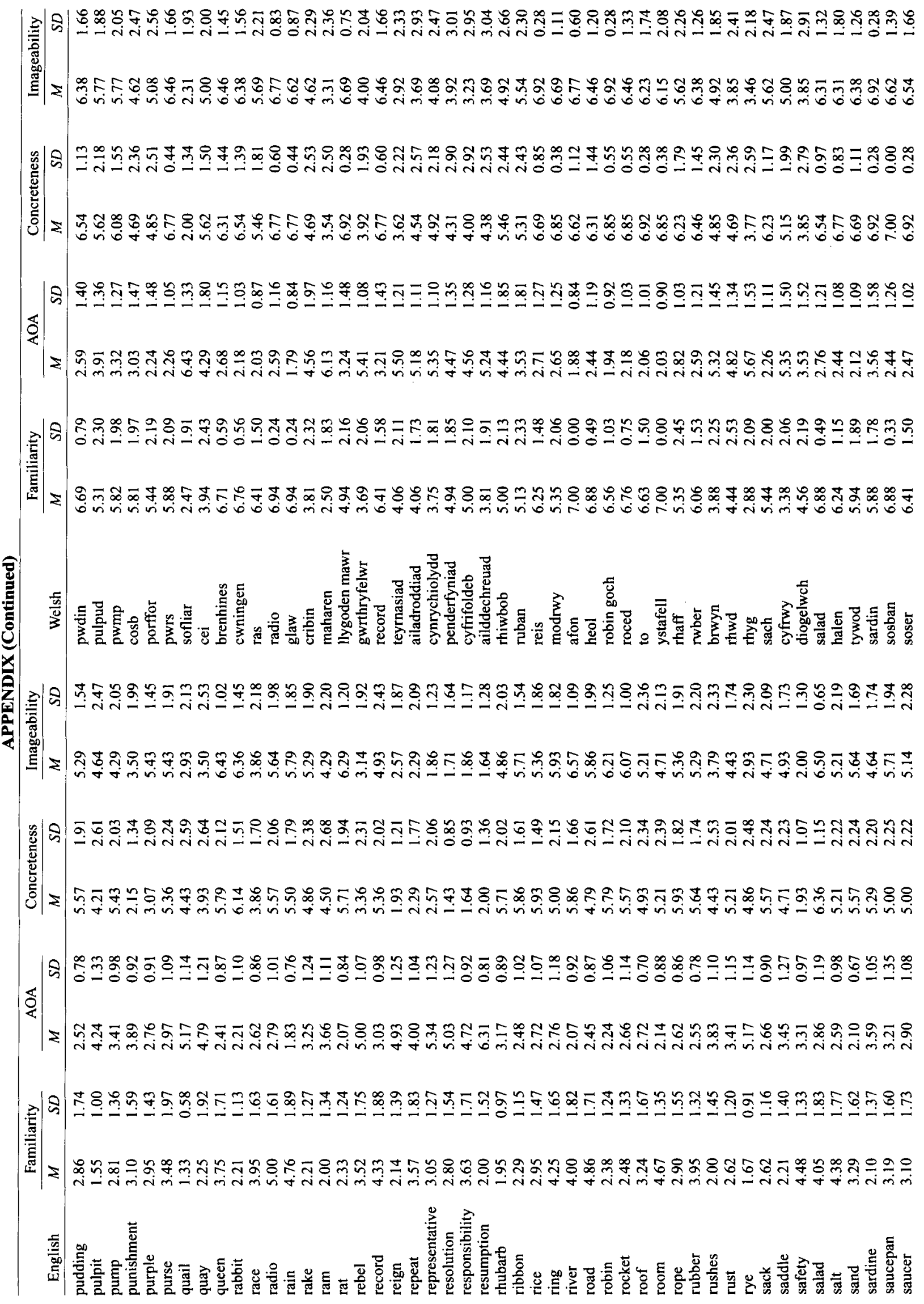




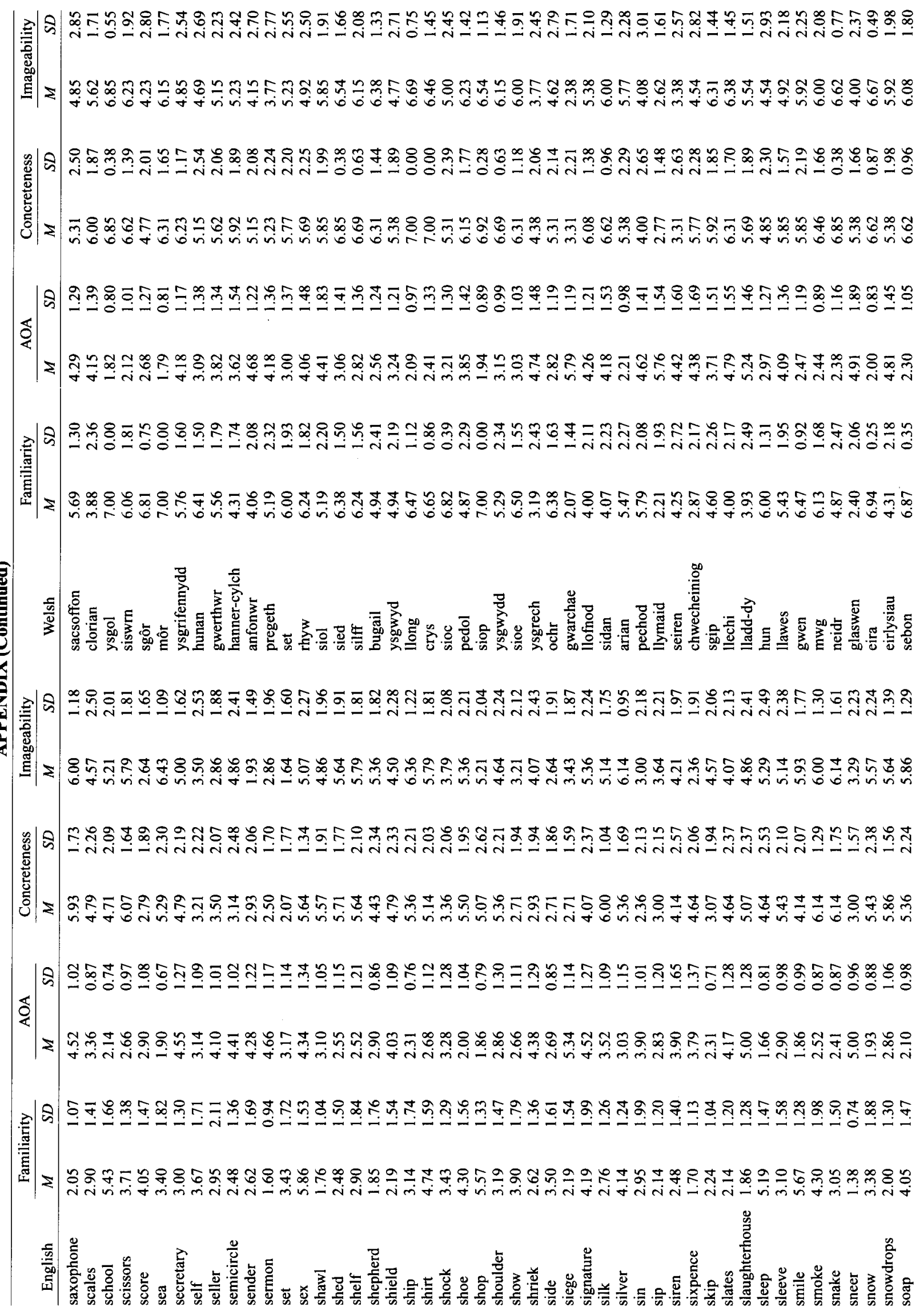




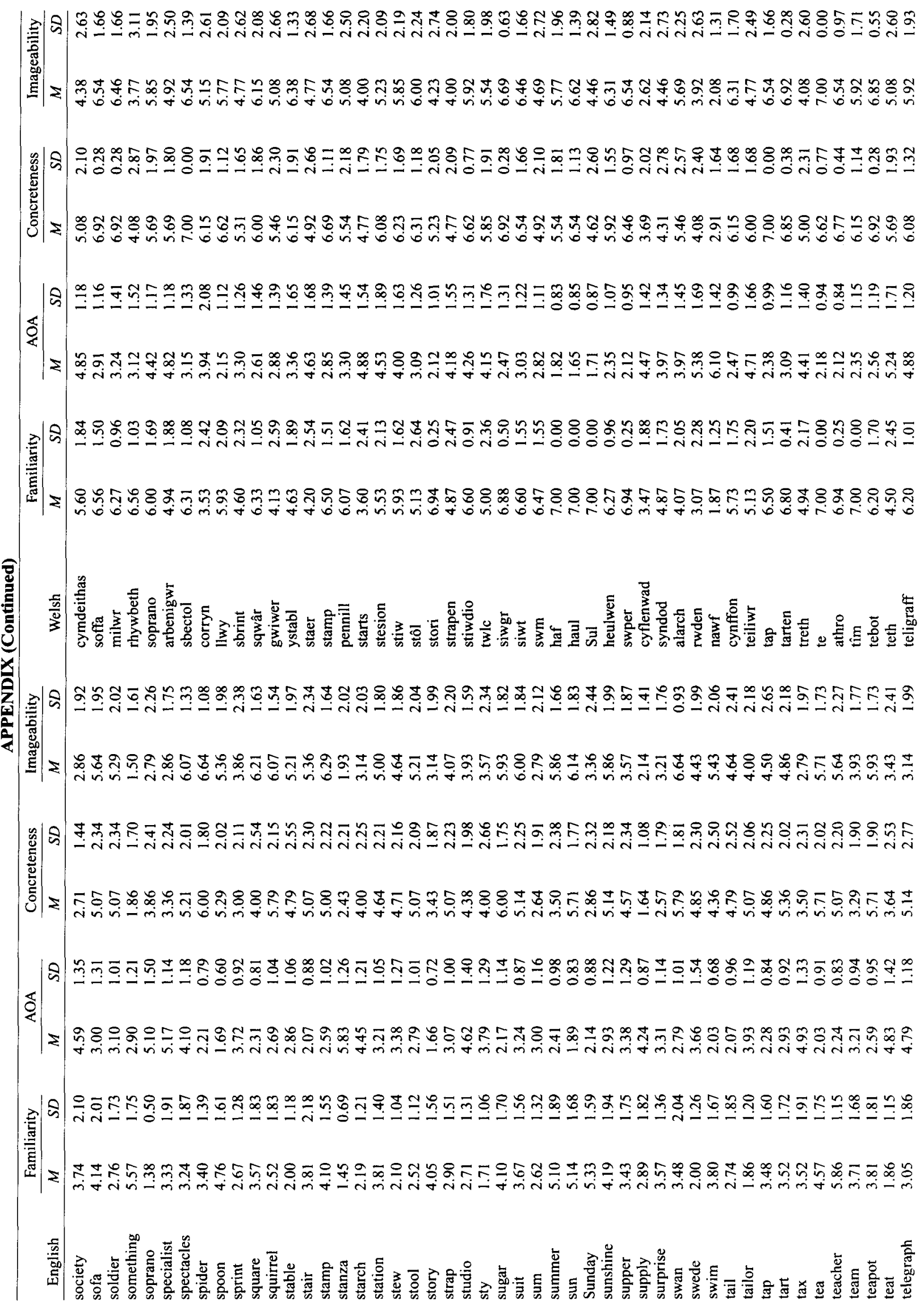




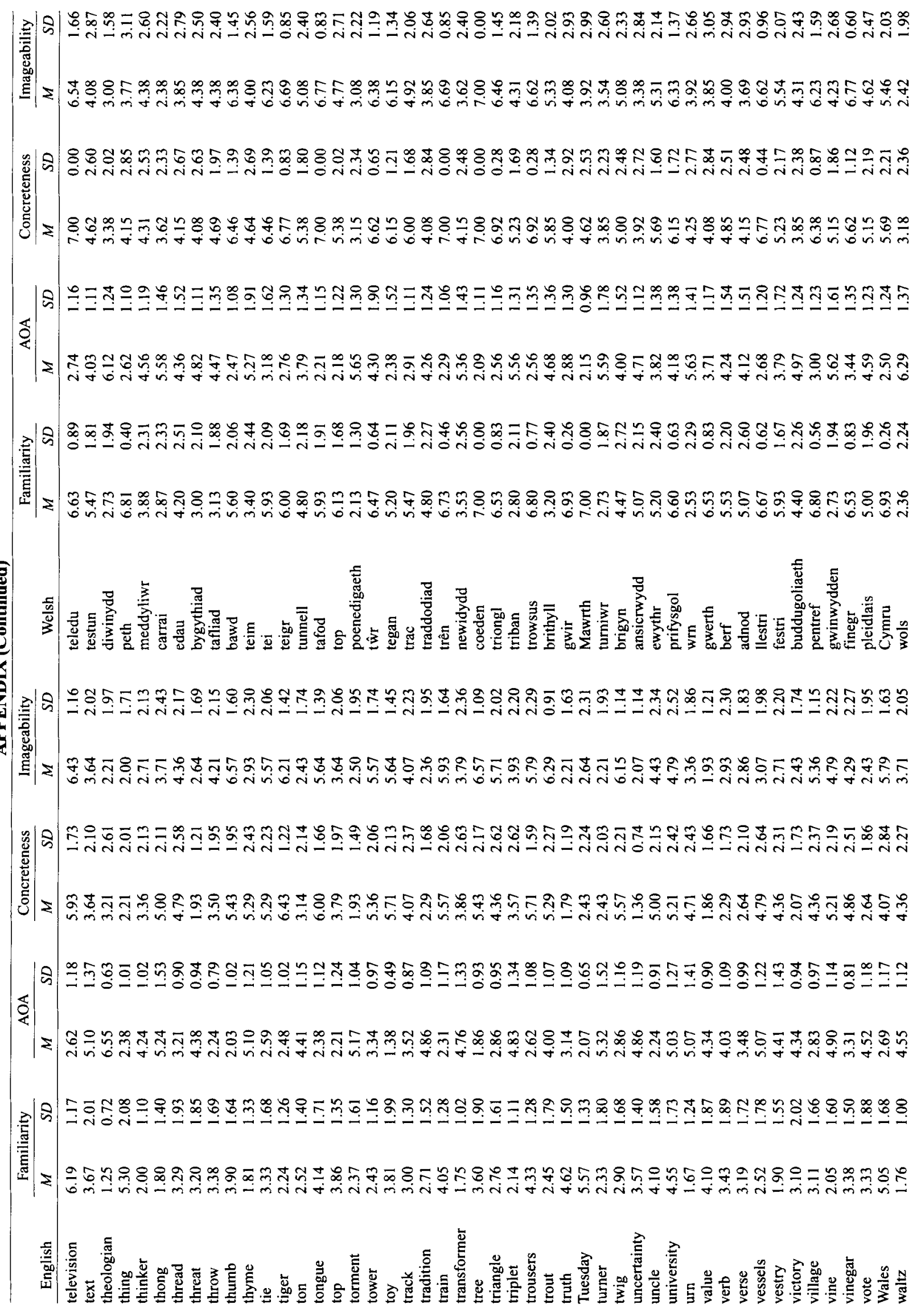




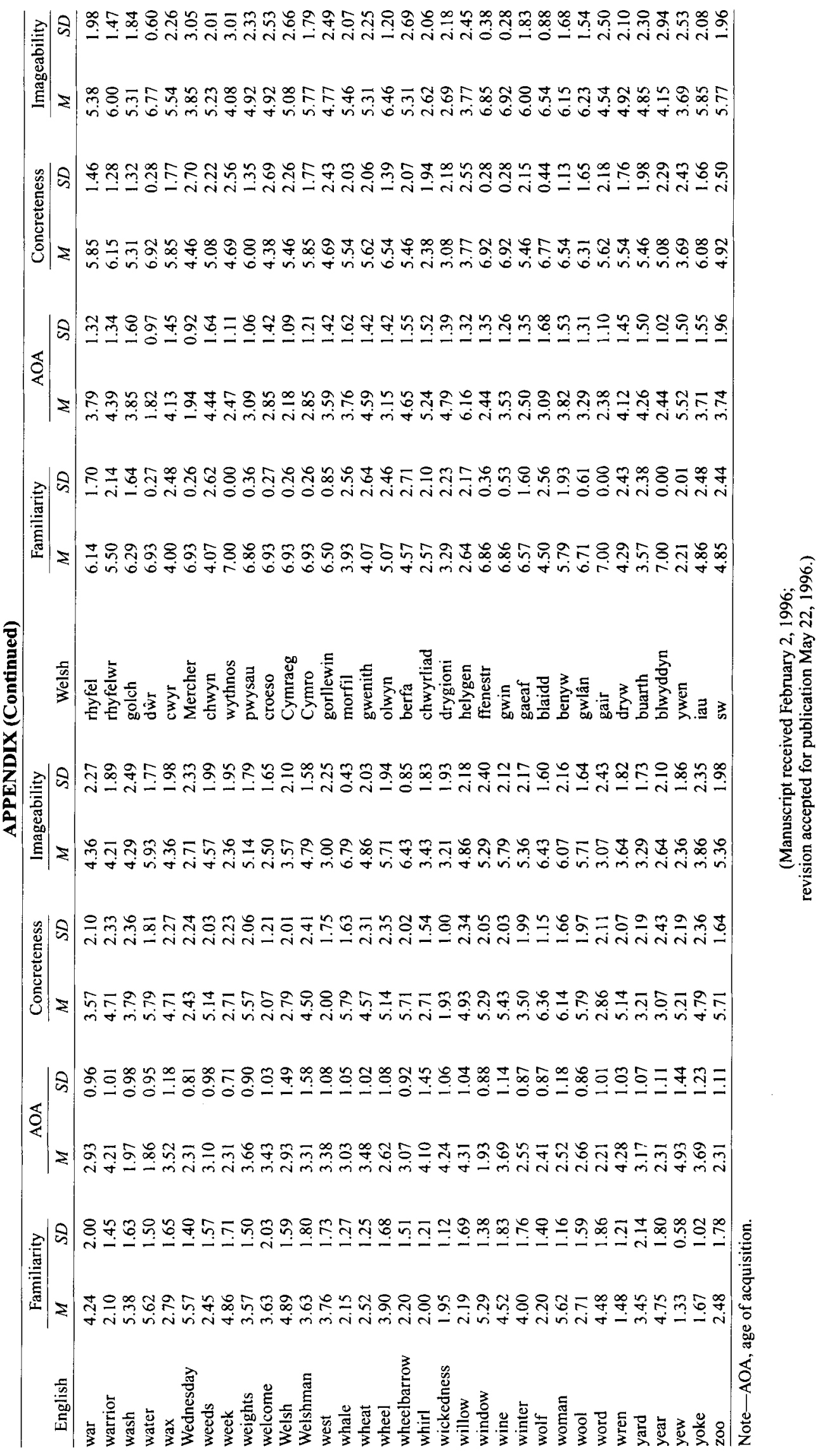

